This is a self-archived version of an original article. This version may differ from the original in pagination and typographic details.

Author(s): Vironkannas, Elina; Liuski, Suvi; Kuronen, Marjo

Title: The contested concept of vulnerability : a literature review

Year: 2020

Version: Accepted version (Final draft)

Copyright: @ 2018 Taylor \& Francis

Rights: In Copyright

Rights url: http://rightsstatements.org/page/InC/1.0/?language=en

Please cite the original version:

Vironkannas, E., Liuski, S., \& Kuronen, M. (2020). The contested concept of vulnerability : a literature review. European Journal of Social Work, 23(2), 327-339.

https://doi.org/10.1080/13691457.2018.1508001 
To cite the published article: Elina Virokannas, Suvi Liuski \& Marjo Kuronen (2018): The contested concept of vulnerability - a literature review, European Journal of Social Work, DOI: $10.1080 / 13691457.2018 .1508001$

Elina Virokannas

Faculty of Social Sciences, University of Helsinki, Finland

Suvi Liuski and Marjo Kuronen

Department of Social Sciences and Philosophy, University of Jyvaskyla, Finland

\section{The contested Concept of Vulnerability - A literature review}

\section{Introduction}

The concept of vulnerability is widely used in academic research as well as in policy making, health and social care services, and in social work (Brown, Ecclestone, \& Emmel, 2017; Hutcheon \& Lashewicz, 2014; Schröder-Butterfill \& Marianti, 2006). Individuals or groups who need support with social, health or economic problems are often defined as vulnerable. Vulnerability is also used to justify the right to receive certain benefits or to gain access to services or treatment.

However, definitions of who is seen as vulnerable and for what reasons vary enormously. Children and young people, elderly people, ethnic minorities as well as groups of people being exposed to hazards like environmental disasters are often understood as being vulnerable. In fact, vulnerability as an analytical concept first emerged in the environmental sciences in reference to the impact of natural or economic disasters on human populations (Wisner, 1993). In addition, the concept is used in medicine and public health as an epidemiological term (Hutcheon \& Lashewicz, 2014). There are also researchers who argue 
that vulnerability should be seen as universal human condition instead of defining certain people or groups as being vulnerable (Fineman 2008, 2010 and 2013; Herring 2016). Herring proposes that there are two main schools of thought, with the first emphasising universal vulnerability and the other focusing on certain people or groups as vulnerable (Herring, 2016).

Because of its various meanings and contexts, the concept of vulnerability has been criticised by many authors as being contested and unclear. It has been claimed to be too loose in policy contexts (Kirby, 2006) and in social work and social care practice (McLaughlin, 2007), to lack analytical clarity (Brown et al., 2017) and for being used in a stigmatising way when referring to individuals or groups and associated with victimhood, deprivation, dependency or pathology (Fawcett, 2009; Munro \& Scoular, 2012).

Our interest in the concept of vulnerability arises from our position as social work academics who study people in marginalised and vulnerable position in the society and services directed for them. As social work researchers, we should be theoretically and ethically careful with our use of concepts, aware of the consequences, and choose ones that do not label or stigmatise We argue that in most social work literature, vulnerability is used without properly defining it and the consequences of such naming and conceptualising are not always carefully reflected on. It is also crucial to acknowledge that the use of concepts such as vulnerability have firm connections with and consequences to social work practice (Brown, 2011; Hutcheon \& Lashewicz, 2014). However, we are more interested in and focused on the use of the concept in academic research rather than in social work practice.

More analytical consideration and interest in developing the concept has occurred recently (e.g. Fineman, 2010; Brown, 2017; Herring, 2016). Our aim is to contribute to that development and critical discussion. Thus, we undertook a literature review on how vulnerability has been used and defined in academic articles published in international social 
scientific journals since the year 2000. We decided not to focus only on social work journals as we wanted to find out if there are new and innovative ways of using and defining the concept in other contexts and disciplines. We ask what themes and topics are connected to vulnerability, how gender is related to vulnerability and how vulnerability is conceptualised in these academic articles, which is the focus of our analysis.

\section{Methodology}

There are several ways to conduct a literature review, and they can be applied to multiple types of questions (e.g. Van Wee \& Banister, 2015). We adopted for a systematic approach (Aveyard, 2014; Petticrew \& Roberts, 2006) (see Figure 1). Test searches in electronic databases such as Academic Search Elite, Sociological Abstracts, Social Services Abstracts, JSTOR and IngentaConnect showed that there has been a huge amount of publishing related to vulnerability from many perspectives. The substantial number of publications underpinned the need to limit the search results to a manageable size.

Alongside our research questions, the test searches helped us to determine the appropriate inclusion and exclusion criteria (Aveyard, 2014). We decided to focus on articles in which vulnerability is conceptualised, not just briefly mentioned or taken for granted. Thus, the final inclusion criteria for the articles were that they should be peer-reviewed articles published in English-language in scholarly journals in which the concept of vulnerability applies to people or their life situations and is being defined. To concentrate on recent publications and to limit the search results, we only included articles that were published from 2000 onwards. The search term used was vulnerability OR vulnerable (=keyword). The search was conducted in October 2016 using Sociological Abstracts and Social Services Abstracts databases. 
The search yielded 479 articles without duplicates. Two of the authors scanned through the publications to find out if they met our inclusion criteria and placed the relevant articles to be included into several categories according to their topic. At this point, we excluded papers which were not research articles, could not be found as full text or were subject to charge, did not concern people or their life situations or in which the concept was not defined at all. The latter two were the most common reasons for exclusion. For example, we excluded articles in which vulnerability was used only as a synonym for risk and which therefore had a distinct perspective, often concerning health issues such as vulnerability to certain disease or to environmental problems (e.g. Blumstein, Benyamini, Boyko \& LernerGeva, 2015; Maziarz, Chertow, Himmelfarb \& Hall, 2014; Adelekan, 2012). After this phase, 113 articles were left. During the next stage, we scrutinised these articles more carefully and wrote short summaries of them from the scope of our research questions. More articles were excluded after this closer examination.

Eventually, 86 articles were included in our review. Most of these articles, classified by the first author, came from the US and UK: 30 and 23 respectively. In addition, five articles came from Canada, four from South Africa, three from Australia, three from Belgium and three from Ireland. The remaining 15 articles came from a wide range of European countries (France, the Netherlands, Norway, Slovenia, Sweden, and Switzerland) and beyond (India, Kenya, New Zealand, South Korea, Tanzania, and Trinidad).

\section{Figure 1: The process of literature review (to feature here)}

Literature reviews have their limitations. Our review does not necessarily contain all the relevant studies although it was accomplished following good ethical practice and methodological guidelines. Data collection required balancing between including all the 
relevant articles and limiting the number of the most relevant. Formulating the search term was a challenge because we wanted to limit the results to studies in which vulnerability applies to people or their life situations. Eventually, we had to scan through all the articles to decide if they met our criteria - most of them did not. Thus, we decided to search for articles by keyword since keywords are good indicators of the content and have been chosen by the authors themselves. However, this means that the review missed articles in which the search term is not keyword.

Another limitation is that our data consist only of journal articles and not of books and book chapters. Furthermore, our decision to limit the search into articles written in English excluded publications in other languages. However, there were also studies undertaken outside the English-speaking countries. Despite these limitations, we found that the review covered well the use and conceptualisation of vulnerability in social scientific research.

\section{Who are vulnerable?}

Some identification of vulnerable groups was found in almost all the articles. Authors usually focused on a specific group of people. Brown (2017) makes a distinction between approaches that focus on either natural or innate vulnerability or situational vulnerability. The former tends to position certain groups of people in permanent risk situations, whereas situational vulnerability refers to particular circumstances. In our data, vulnerability was categorised either by 'natural' characteristics of people, such as age, sex or disability, or by situational aspects like social, economic and living conditions.

Concerning specific groups, the largest number of articles (19) discussed children and young people. Geographically, those studies were located on six different continents including Africa, Europe, Australia, South America, North America and East Asia. Groups of 
children and young people categorised and studied as vulnerable included orphans (Baaroy \& Webb, 2008), street children (Malindi \& Cekiso, 2014), child soldiers in Africa (Johannessen \& Holgersen, 2014) and young people in transition to adulthood (Berzin, 2010).

The second largest group seen as vulnerable comprised elderly people (11 articles). These studies had mainly been undertaken in European countries. Elderly people were defined as vulnerable due to their frailty and their often-unmet need for care. The aspects of vulnerability addressed were low income, socio-economic status, poor social relationships, weak autonomy, chronic illness and poor quality of life. (E.g., Grundy, 2006; Kreager \& Schröder-Butterfill, 2007.)

The third topic concerned women in different life situations. There were seven such articles, three of which were studies of motherhood. These studies were located in the US and Europe, with one from Africa. Various groups of women were defined as vulnerable, such as female war survivors in Kosovo (Kellezi \& Reicher, 2014) or, as in the context of the US abortion policy, adolescents, women of colour, women living in rural areas or suffering from economic disadvantage (Ely \& Dulmus, 2010). Articles also covered topics such as refugee women in Africa (Jaji, 2015) and incarcerated mothers (Few-Demo \& Arditti, 2014).

Vulnerability was often connected with other concepts, especially victimhood and risk. In four articles, vulnerability was viewed from the perspective of being a risk of becoming a victim of crime, particularly violence and abuse. These studies included hate crime victimisation and its conceptualisation (Chakraborti \& Garland, 2012) and the interrelationship between criminal victimisation, vulnerability and resilience (Walklate, 2011). Hollomotz (2012) studied the risk of violence related to disabled people, and argues that individual vulnerability is often seen as an explanation for an increased risk of violence which ignores the social conditions, such as power imbalance and marginalisation behind the violence and its risk. These articles had an analytical and sometimes a critical tone 
concerning victimhood and its connection with vulnerability. The concept of risk was used in various meanings in relation to vulnerability (e.g., Fawcett, 2009; McLaughlin, 2007), with it often referring to Beck's (1992) concept and idea of risk society.

One specific topic was the vulnerability of research participants. Three of the articles focused explicitly on research ethics when doing research with vulnerable informants such as psychiatric patients (Oeye, Bjelland, \& Skorpen, 2007), impoverished youth in a South African township (Swartz, 2011) and refugees (Perry, 2011). In these articles, it was taken for granted that these groups are vulnerable, and the authors discussed how to develop and use research strategies that would allow their active participation. Oeye, Bjelland and Skorpen (2007) criticised the situation that required researchers to follow medical ethical guidelines when studying certain vulnerable groups (such as patients in psychiatric hospitals), and demanded guidelines that would fit better into social science research. It was also acknowledged that participants defined as vulnerable might not perceive themselves in the same way (Aldridge, 2014). These ethical considerations are important for social work research, but they should go even further to discuss the actual use and definition of the concept of vulnerability.

Less often mentioned groups of people defined as vulnerable were men in different life situations, such as young fathers with low educational and income levels (Devault et al., 2008), and young men in relation to women's emphasized femininity (Korobov, 2011). There were also studies concerning poverty, people with learning difficulties, transgender people, HIV-positive people and immigrants. Single topics were prisoners, substance abusers, and social workers and their clients, families and widows.

In addition, some of the articles discussed vulnerability from quite diverse perspectives, some dealing with multiple groups of people (e.g. Buck, Balmer, \& Pleasence, 2005) and some not focusing on any specific group but assessing larger geographical or other 
populations (e.g. Galea, Ahern, \& Karpati, 2005). However, this overview of the themes and topics in the articles reviewed shows the huge variety of individuals, groups or life situations that have been studied under the 'label' of vulnerable or vulnerability. The countless fields of study, methodologies and ways of using the concept overall vary to such an extent that it raises a critical question concerning the analytic power of the concept since almost anything or anyone can be defined as vulnerable (see also Herring 2016). It would be important to analyse further, what these people, groups, or situations share in common, and what is the common ground of the concept of vulnerability.

\section{Vulnerability and Gender}

Our analysis of the themes and topics of the articles showed that women or men in certain social situations or life stages have been defined as vulnerable. One of our research interests concerns how gender is related to vulnerability, and whether and how the connection between gender and vulnerability has been theorised. We find this to be important, as there is often no proper theorising of gender when social problems, welfare services and people in vulnerable life situations are studied (Orme 2003). There are strong cultural and moral expectations regarding adequate womanhood and motherhood, which influence the ways women are seen as service users (e.g. Smith, 2006; Lavee, 2017). Several previous studies have shown that men and women are met and worked with differently in the welfare service system. For example, women with substance use disorders are more likely to face multiple barriers affecting access and entry to treatment (Stone, 2015; Tuchman, 2010).

Half of the studies in our literature review did not address gender at all. Gender was either not mentioned, or both sexes were empirically studied without analysing or conceptualising gender and its connections to vulnerability. In most of the studies concerning 
children and young people, or when vulnerability was related to disabled people, gender was not discussed. In almost a quarter of the studies, vulnerability was related to gender to some extent, but not problematised any further. For example, gender was used as an empirical variable, but in the findings or discussion, gender differences were not considered in relation to vulnerability (Anderson-Butcher \& Cash, 2010; Hall \& Hardill, 2016; Noble-Carr, Barker, Mcarthur, \& Woodman, 2014; Taylor, 2011). Some of the articles were based on empirical studies that included either men or women. In these, vulnerability was related to themes such as old age, widowhood, widowerhood, motherhood, fatherhood, victimhood, transgenderism, poverty and marginalisation (e.g. Devault et al., 2008; Few-Demo \& Arditti, 2014; Van de Walle, 2013).

In some of the articles, men and women were compared, and either women or men mostly women -were defined as being more vulnerable. For example, Kellezi and Reicher (2014), who studied the psychological effects of war, argued that women are psychologically more vulnerable than men in extreme situations because women are more likely to experience identity-undermining events. However, they suggested that vulnerability is not inherent 'of the female psyche, nor does it derive entirely from something inherent in the events that women experience. In part at least, it is tied to gender norms, to the ways in which these govern the interpretation of events in war and the response to them.' (Kellezi \& Reicher, 2014, p. 502.)

Vikström (2006), in her historical study concerning vulnerability among paupers in the nineteenth century in Sweden, also defined women as more vulnerable than men. Unlike Kellezi and Reicher (2012) who stressed psychological vulnerability, Vikström showed how women's vulnerability resulted from their economic and social dependency on menPoor widows or single mothers struggled in combining lone motherhood and work. Men were more protected against vulnerability. 
Widowhood was also mentioned in relation to vulnerability in other articles. Van de Walle (2013), who studied the situation of widows in Mali, Africa, stated that widow-headed households were in a considerably weaker, and persisting, welfare position compared to other households. Van Eeuwijk (2006), who identified old-age vulnerability in relation to risk to inadequate care provision in Indonesia, found that unmarried women and poor widows were the most vulnerable due to their weaker social position in their family and kin.

The studies that addressed widowhood highlighted the significance of women's societal and cultural position in producing or protecting from vulnerability. This was found also in articles that were studies of poverty and social participation where women were seen to be in a vulnerable position and at risk of social exclusion (Bernabè \& Kolev, 2005; Lombe \& Sherraden, 2008; Trani, Bakhshi, Noor, Lopez, \& Mashkoor, 2010). Vulnerability was seen as being related to the weaker and less protected economic situation of women in certain life situations, and also to their care needs.

By contrast, Williams (2009) considered that gender, alongside ethnicity and social class, also had a significant role in men's experiences of vulnerability. He addressed vulnerability from the scope of fatherhood, health concerns, difficulties in relationships and stress. Williams argued that men's experiences were linked to 'uncertainty, confusion, and contradictions about what it means to be a man' (Williams, 2009, p. 459). Due to conservative forms of masculinity, men shared solitary discourses and ways of dealing with their vulnerability to prevent its disclosure to others. However, especially in the context of fatherhood, the discourse was negotiated and challenged. (Williams, 2009.)

Vulnerability was studied not only in relation to actual, tangible social and economic situations or as individual experiences, but also as cultural discourses connected to women and femininity. Such discourses were seen to produce differences and disparity (Schrover, 2009), marginalization of women's experiences (Carlson, 2014) and belittlement of women's 
agency (Jaji, 2015). Victimhood, vulnerability and womanhood were often linked together. For example, Schrover (2009) studied how 'family' had been deployed in Dutch migration policy and argued that migrant women had been constructed in the context of family and victimhood discourse. In part this enhanced their rights, but on the other hand, it labelled them as more vulnerable and in need of protection and hence defined them as 'other' in relation to Dutch women. This kind of analysis recognises differences within gender and does not simply make distinctions between them. Schrover (2009) discussed her findings as follows:

'[v]ulnerability is - of course - a staple element in the construction of (Western) femininity, as is the construction of women as mothers and wives, while men are not primarily constructed as vulnerable, or as fathers and husbands, but as economic actors. Not surprisingly, ideas about proper roles for men and women and about femininity and masculinity affected migration and integration policies.' (Schrover, 2009, p. 200.)

Also, Jaji (2015), who had studied femininities among East and Central African refugee women, argued that refugee women's femininity was not just about vulnerability and 'victimhood'. She stated that while refugee women were vulnerable to sexual and genderbased violence due to their gender, some of them might use their femininity as a resource to gain financial benefits through 'strategic dating'. Therefore, they were not to be seen only as victims, since it would understate their capability to make choices and create alternative femininities.

Carlson (2014) also discussed critically the connections between gender, victimhood and vulnerability and how they are socially constructed. In the context of the US gun policy, she saw the vulnerability discourse as a gendered means to strengthen men's rights and position and marginalise women's experiences. 
Based on our review, there were two main approaches connecting gender and vulnerability in these articles. The first one emphasises social and economic conditions that cause vulnerability and effect women and men differently, while the other one studies vulnerability as socially constructed and related to discourses of femininity and masculinity. However, the definition of the concept of vulnerability itself is not explicitly discussed as gender specific.

\section{Conceptual analysis of vulnerability}

The main focus of this literature review is to find definitions of vulnerability and approaches that do not simply connect vulnerability with certain individuals or groups but that analyse the concept more theoretically and in depth. Many of the articles criticised the way the concept had been used in previous studies (e.g. Hutcheon \& Lashewicz, 2014), in certain practices or in political rhetoric (Heap, 2016), also commenting on its conceptualisation (Aldridge, 2014). Such critique focused for example on ignoring the structural grounds producing vulnerability. Three articles specifically considered structural vulnerability (Koch, 2015; Mishra, 2014; Szkupinski Quiroga et al., 2014) demonstrating how the concept is often used in classifying people in the way that overlooks

'the structural and social processes and institutions that originally created and sustained that very vulnerability' (Koch, 2015, pp. 141).

In this section we emphasise the articles from our data that address what the concept of vulnerability theoretically has to offer. Of the 86 articles included in the review, we found 10 articles that best meet this requirement. The articles focused on vulnerability as a concept in diverse and wide-ranging ways. Some of the authors had a quite critical perspective on how the concept has been used, but others found it particularly useful. 
Three articles discussed the concept of vulnerability through analysing the work of some other theorists (Chouliaraki, 2013; Ferrarese, 2011; Kirby, 2006). Ferrarese (2011) analysed the concept of 'constitutive vulnerability' in Judith Butler's theory of performativity. Chouliaraki (2013) situated her discussion in the context of Habermas' idea of the public sphere, and Kirby (2006) analysed the concept of vulnerability in the context of globalisation, also situating it within Karl Polanyi’s social theory.

Two of the articles were by the same author (Jordan 2008a; 2008b). As a therapist, Jordan viewed vulnerability from a psychological perspective, and argued that vulnerability appears as an essential part of the contemporary society. She clarified her perception by using examples from therapy sessions. Jordan argued that fear, vulnerability and the need for connection, or rather isolation and marginalisation, are linked together. In our contemporary societies, people have been ruled by fear, and isolation has been the primary force of suffering. Vulnerability for Jordan was something that should be recognised and valued, not hidden and feared:

'Vulnerability defines our humanity. Fear signals our vulnerability. Denial of fear and vulnerability creates our most profound alienation from others and ourselves and generates our worst isolation.' (Jordan, 2008a, p. 239.)

Where Jordan saw vulnerability in psychological terms as an inevitable part of being alive, as social scientists, Fawcett (2009) and Brown (2011) discussed vulnerability from a quite different and critical point of view. Both also discussed it not only as a scientific concept, but as a concept that is closely linked with policy and practice. Referring to Dunn, Clare and Holland (2008) Fawcett described how the concept of vulnerability has been incorporated into legislation and embedded within policy and practice frameworks in a way that can 'reduce a person's life to a series of risk factors' (Fawcett, 2009, p. 474). 
Social work and social policy researchers in the UK have often connected their critical analysis with the national, official legal and administrative definition of 'vulnerable people', which has had consequences for the service provision and professional practice (e.g. Brown, 2011; Fawcett, 2009; Hollomotz, 2009). Their aim has been not only to theorise the concept, but to analyse its use in practice and the consequences of such a definition. Both Fawcett (2009) and Brown (2011) have stated that assessing people as vulnerable was meant to ease service provision for people needing support. However, vulnerability has often been associated with negative conditions and implies weakness. Thus, paying attention to weaknesses rather than strengths has created dependency and passivity and eroded autonomy.

In her article, Brown (2011) has made a detailed analysis of the concept and presents arguments why it 'should be handled with care'. First, the concept has been used in patronising and oppressive ways, especially concerning disabled people and people with learning difficulties. The use of the concept has strengthened the impression of individuals as incapable, limited and deficient. Secondly, she considered the concept to have controlling functions as it justifies interventions and 'knowing better' what is best for people defined as vulnerable. Thirdly, it has acted to exclude and stigmatise individuals or groups. Brown emphasised that the concept is by no means value-free, but that there are strong ethical implications tied to it. In addition, she stated that '...presumed inherent vulnerability can function as an excuse for failing to tackle structural vulnerabilities' (Brown, 2011, pp. 318-319). She concludes, in line with our argument, that

'It's time to sharpen up the research agenda on vulnerability. Academics in the social sciences need to stop concentrating on it as something that is pre-existing in reality and able to be identified by scientific or social measurement and indicators, and start interrogating the conceptual boundaries of the notion.' (Brown, 2011, p.319) 
Still, Brown does not go further in defining how vulnerability should be conceptualised and used as a social science concept. However, she has more recently continued her critical analysis and development of the concept (Brown, 2017).

Brown (2011) called for more knowledge and awareness of how service users themselves find labelling as vulnerable. Also Fawcett (2009) emphasised the importance of working in partnership with people, instead of presenting vulnerability as an objective fact and labelling individuals or groups from the outside. According to her, authorities and professionals should acknowledge the personal experiences of individuals concerning their needs and strengths instead of focusing on their functional incapacity. This is also an important reminder for researchers.

Schröder-Butterfill and Marianti (2006) developed a systematic framework for approaching vulnerability in the context of old age. They recognised the same risks as Fawcett (2009) and Brown (2011) when using the concept, as it might be used as an 'illdefined descriptor' (p. 14), which confirms disadvantages of individuals or groups. They also stated that the views of older people might differ from outside definitions and ask who is supposed to define who is vulnerable, and vulnerable to what. However, Schröder-Butterfill and Marianti (2006) found the concept remarkably less risky and emphasised its positive potential. In their framework, vulnerability

'arises from combinations of characteristics and, importantly, from interactions between exposure, threats and coping in specific contexts' (Schröder-Butterfill \& Marianti, 2006, p. 18).

They argued that vulnerability differs from other social science concepts that describe 'negative states' (p. 28). Instead, the emphasis has been on preventing the negative and undesirable outcomes through focusing on coping capacities. 
While Schröder-Butterfill and Marianti (2006) emphasised the usefulness of the concept, Carlson (2014), in the very different context of gun politics, shared the concerns of Fawcett (2009) and Brown (2011). As mentioned earlier, Carlson criticised connecting victimhood and vulnerability. Instead, she used the concept of 'vulnerability politics' as a theoretical framework to explain and understand how social construction of crime reproduces masculine privilege. Carlson described vulnerability politics as 'a particular kind of political frame for making universalistic claims based on embodied vulnerability' (Carlson, 2014, p. 61) and sees vulnerability as a 'rallying cry for privileged interests to wedge political claims' (p. 64).

Like Jordan (2008a; 2008b), Carlson (2014) defined vulnerability as a universal aspect of human life. However, in contrast to Jordan who addressed vulnerability as an inherited characteristic, Carlson (2014) emphasised that vulnerability is socially constructed as 'universal' by dominant interests and can thus be used in a way that enables only certain standpoints and experiences to be recognised and leads to marginalising and ignoring others. In the context of gun and crime discourses, according to Carlson, it means marginalising feminine voices, experiences of domestic violence and intersectional differences.

Kirby (2006), whose viewpoint differs considerably from that of previous researchers, addressed vulnerability from the perspective of globalisation. He found the concept to be a useful tool for analysing the distinctive social impacts that globalisation is having on societies. For him, the potential of the concept lies in its relational nature:

Unlike security, the concept of vulnerability does not express a state to be achieved '[...] It therefore points, not to the attempt to make ourselves invulnerable which is unattainable, but to strengthen the means by which we might cope with the threats to which we are vulnerable.' (Kirby, 2006, pp. 645-646.) 
As Kirby emphasised the importance of strengthening coping mechanisms, his understanding of vulnerability comes close to that of Schröder-Butterfill and Marianti (2006), even though the contexts of the two studies are quite different.

Both Kirby (2006) and Vikström (2006) considered vulnerability to be a multidimensional concept. It can contribute to capturing both individual and structural aspects of poverty and the factors leading to it. Thus, Vikström (2006) related vulnerability not only to poverty as such, but also to environmental, societal and socio-economic factors during an individual life cycle. She saw vulnerability as limiting individual agency but there are also opportunities to act and negotiate, which highlight the importance to acknowledge our own preconceptions of people in certain situations.

As shown in this analysis, the articles that discussed the concept of vulnerability in more depth approached it from very different angles. Most of the articles share the criticism of the individualistic use of the concept, and instead point out structural causes and social processes that construct vulnerability.

\section{Conclusions}

This literature review confirms assumptions concerning vulnerability as a 'fashionable' concept, not only in social work research but also in several other disciplines, or as Herring even puts it 'vulnerability has become one of the words of the age' (Herring 2016, p.5).

The main aim of this review was to find new and more theoretically firm ways to conceptualise vulnerability. What we found instead was that in most of the articles, vulnerability was used in a self-evident manner, referring to certain people or groups. However, we also found interesting and important critical commentary on the concept (especially Brown, 2011; Carlson, 2014; Fawcett, 2009; Kirby, 2006). Even if some authors 
found the concept of vulnerability useful and promising, many of them discussed the danger of using it in a stigmatising, labelling, marginalising and objectifying way, denying the agency and voice of those seen as vulnerable. This is serious critique, which raises theoretical, methodological and ethical challenges for social work research, which is often studying people labelled as vulnerable, their everyday life, social problems, and services directed for them. As social work researchers, we should choose concepts and theoretical approaches that are empowering for the people we are studying. This should begin with their own experiences and understanding, but should also helping them to see how social relations, structures and institutions control and organise their everyday world (Smith, 1987). It should be acknowledged that people, including those considered and constructed as 'extremely vulnerable' are capable of acting and expressing their own thoughts concerning their presumed 'vulnerability', if only that opportunity is given to them (Hoffman, 2012; Wernesjö, 2012).

We argue that there is still a need to take a step further from these critical concerns. In the Introduction, we referred to Herring (2016) according to whom there are two major schools of thought in conceptualising vulnerability. The first school, which defines certain people or groups as vulnerable, was dominant in our review. The other, which emphasises universal vulnerability (Fineman, 2008, 2010, 2013; Herring 2016), was almost non-existent, and when it was referred to, it was done in a psychologically or even therapeutically oriented manner (Jordan 2008a and b).

We find the idea of universal vulnerability to be very promising to further conceptualise and study vulnerability, especially the way in which it has been developed by Martha Fineman. Fineman (2010) defines universal, human vulnerability that 'arises from our embodiment, which carries with it the imminent or ever-present possibility of harm, injury, and misfortune' (p. 267). Still, she does not deny that some individuals or groups are more 
vulnerable than others. For her, vulnerability is both universal and particular. It is a complex phenomenon, which manifests itself in many forms, and can be accumulated and transferred generationally. Fineman also uses vulnerability as a relational concept, referring to relationships between individuals but especially between individuals and the society (Fineman, 2008 and 2010).

What we find most important in her conceptualisation is that she focuses on the social processes generating vulnerability and the responsibility of the state and its institutions in reducing the risks and consequences of vulnerability. Consequently, she argues that 'vulnerability analysis must consider both individual position and institutional relationships.' (Fineman, 2010, p. 269.)

Following Fineman, we argue that in analysing vulnerability, attention should be turned towards vulnerable life situations, social processes, society and its institutions, including social work and the entire welfare service system. These compensate for, but possibly also generate and (re)produce vulnerability. It is also important to recognise the temporal, situational, relational and structural nature of vulnerability. We further argue that gendered practices and relationships in the society should be an essential part of this type of analysis, a factor that too often seems to stay unproblematised when vulnerability is in question. We suggest that this is a promising way forward to reconsider and reformulate the concept of vulnerability of social work research.

\section{References}


Adelekan, I. O. (2012). Vulnerability to wind hazards in the traditional city of Ibadan, Nigeria. Environment \& Urbanization 24(2), 597-617. doi: $\underline{10.1177 / 0956247812454247}$

Aldridge, J. (2014). Working with vulnerable groups in social research: Dilemmas by default and design. Qualitative Research, 14(1), 112-130. doi: 10.1177/1468794112455041

Anderson-Butcher, D., \& Cash, S. J. (2010). Participation in Boys \& Girls Clubs, vulnerability, and problem behaviors. Children and Youth Services Review 32(5), 672-678. doi: 10.1016/j.childyouth.2010.01.002

Aveyard, H. (2014). Doing a literature review in health and social care: A practical guide (3nd Edition). Maidenhead: Open University Press.

Baaroy, J., \& Webb, D. (2008). Who are the most vulnerable? Disaggregating orphan categories and identifying child outcome status in Tanzania. Vulnerable Children and Youth Studies, 3(2), 92-101. doi: $\underline{10.1080 / 17450120802195359}$

Beck, U. (1992). Risk society: Towards a new modernity. London: Sage. Bernabè, S., \& Kolev, A. (2005). Jobless or working poor in the Kyrgyz labour market: What role for social policies? Social Policy \& Administration, 39(4), 409-430. doi: 10.1111/j.1467-9515.2005.00447.x

Berzin, S. (2010). Vulnerability in the transition to adulthood: Defining risk based on youth profiles. Children and Youth Services Review, 32(4), 487-495. doi: 10.1016/j.childyouth.2009.11.001

Blumstein, T., Benyamini, Y, Boyko, V. \& Lerner-Geva, L. (2015). Women’s knowledge about heart disease: Differences among ethnic and cultural groups in the Israeli Women's Health in Midlife Study. Women \& Health, 56(1), 78-97. doi: $10.1080 / 03630242.2015 .1074639$ 
Brown, K. (2011). 'Vulnerability': Handle with care. Ethics and Social Welfare, 5(3), 313-321. doi: $10.1080 / 17496535.2011 .597165$

Brown, K. (2017). Vulnerability \& Young People. Care and social control in policy and practice. Bristol: Policy Press.

Brown, K., Ecclestone, K., \& Emmel, N. (2017). The many faces of vulnerability. Social Policy and Society, 16(3), 497-510. doi: 10.1017/S1474746416000610

Buck, A., Balmer, N., \& Pleasence P. (2005). Social exclusion and civil law: Experience of civil justice problems among vulnerable groups. Social Policy Administration, 39(3), 302-322. doi: 10.1111/j.1467-9515.2005.00441.x

Butler, J. (2004). Precarious life: The powers of mourning and violence. London and New York: Verso.

Carlson, J. (2014). The equalizer? Crime, vulnerability, and gender in pro-gun discourse. Feminist Criminology, 9(1), 59-83. doi: 10.1177/1557085113502518

Chakraborti, N., \& Garland, J. (2012). Reconceptualizing hate crime victimization through the lens of vulnerability and "difference". Theoretical Criminology, 16(4), 499-514. doi: $\underline{10.1177 / 1362480612439432}$

Chouliaraki, L. (2013). Mediating vulnerability: Cosmopolitanism and the public sphere. Media, Culture, and Society, 35(1), 105-112. doi: 10.1177/0163443712464564

Devault, A., Milcent, M-P., Ouellet, F., Laurin, I., Jouron, M., \& Lacharite, C. (2008). Life stories of young fathers in contexts of vulnerability. Fathering. A Journal of Theory Research and Practice about Men as Fathers, 6(3), 226-248. doi:

10.3149/fth.0603.226

Dunn, M. C., Clare, I. C. H., \& Holland, A. J. (2008). To empower or to protect? Constructing the 'vulnerable adult' in English law and public policy. Legal Studies 28(2), 234-253. doi: 10.1111/j.1748-121X.2008.00085.x 
Ely, G. E., \& Dulmus, C. N. (2010). Abortion Policy and Vulnerable Women in the United States: A Call for Social Work Policy Practice. Journal of Human Behavior in the Social Environment, 20(5), 658-671. doi: 10.1080/10911351003749177

Fawcett, B. (2009). Vulnerability: Questioning the certainties in social work and health. International Social Work, 52(4), 473-484. doi: 10.1177/0020872809104251

Ferrarese, E. (2011). Judith Butler's "not particularly postmodern insight" of recognition. Philosophy \& Social Criticism, 37(7), 759-773. doi: 10.1177/0191453711410029

Few-Demo, A., \& Arditti, J. (2014). Relational vulnerabilities of incarcerated and reentry mothers: Therapeutic implications. International Journal of Offender Therapy and Comparative Criminology, 58(11), 1297-1320. doi: 10.1177/0306624X13495378

Fineman, M. A. (2008). The vulnerable subject: Anchoring equality in the human condition. Yale Journal of Law \& Feminism, 20(1), 1-24; Emory Public Law Research Paper No. 8-40. Available at SSRN: https://ssrn.com/abstract=1131407

Fineman, M. A. (2010). The Vulnerable Subject and the Responsive State. Emory Law Journal 60 (2), 251-275; Emory Public Law Research Paper No. 10-130. Available at SSRN: $\underline{\text { https://ssrn.com/abstract=1694740 }}$

Fineman, M. A. (2013). Equality, Autonomy, and the Vulnerable Subject in Law and Politics. In M.A. Fineman and A. Grear (Eds.) Vulnerability: Reflections on a New Ethical Foundation for Law and Politics. pp. 13-28. Surrey: Ashgate.

Galea, S., Ahern, J., \& Karpati, A. (2005). A Model of underlying socioeconomic vulnerability in human populations: evidence from variability in population health and implications for public health. Social Science \& Medicine, 60, 2417-2430. doi: $\underline{10.1016 / \text { j.socscimed.2004.11.028 }}$

Grundy, E. (2006). Ageing and vulnerable elderly people: European perspectives. Aging \& Society, 26(1), 105-134. doi: 10.1017/s0144686x05004484 
Hall, K., \& Hardill, I. (2016). Retirement migration, the 'other' story: Caring for frail elderly British citizens in Spain. Ageing and Society, 36(3), 562-585. doi: https://doi.org/10.1017/S0144686X14001342

Heap, V. (2016). Putting victims first? A critique of Coalition anti-social behaviour policy. Critical Social Policy, 36(2), 246-264.

Herring, J. (2016). Vulnerable Adults and the Law. Oxford: Oxford University Press.

Hoffman, D. M. (2012). Saving children, saving Haiti? Child vulnerability and narratives of the nation. Childhood, 19(2), 155-168. doi: 10.1177/0907568211415297

Hollomotz, A. (2012). Disability, Oppression and Violence: Towards a Sociological Explanation. Sociology 47(3), 477-493. doi: 10.1177/0038038512448561

Hollomotz, A. (2009). Beyond 'Vulnerability': An ecological model approach to conceptualizing risk of sexual violence against people with learning difficulties. The British Journal Social Work, 39(1), 99-112. doi: 10.1093/bjsw/bcm091

Hutcheon, E., \& Lashewicz, B. (2014). Theorizing resilience: Critiquing and unbounding a marginalizing concept. Disability \& Society, 29(9), 1383-1397. doi:

\section{$\underline{10.1080 / 09687599.2014 .934954}$}

Jaji, R. (2015). Normative, agitated, and rebellious femininities among East and Central African refugee women. Gender, Place and Culture, 22(4), 494-509. doi: 10.1080/0966369X.2014.885886

Johannessen, S., \& Holgersen, H. (2014). Former child soldiers' problems and needs: Congolese experiences. Qualitative Health Research, 24(1), 55-66. doi: $\underline{10.1177 / 1049732313513655}$

Jordan, J. V. (2008a). Commitment to connection in a culture of fear. Women \& Therapy, 31(2-4), 235-254. doi: $10.1080 / 02703140802146423$ 
Jordan, J. V. (2008b). Valuing vulnerability: New definitions of courage. Women \& Therapy, 31(2-4), 209-233. doi: 10.1080/02703140802146399

Kellezi, B., \& Reicher, S. (2014). The double insult: Explaining gender differences in the psychological consequences of war. Peace and Conflict: Journal of Peace Psychology, 20(4), 491-504. doi: 10.1037\%2Fpac0000043

Kirby, P. (2006). Theorising globalisation's social impact: proposing the concept of vulnerability. Review of International Political Economy, 13(4), 632-655. doi: $\underline{10.1080 / 09692290600839915}$

Koch, E. (2015). Protracted displacement in Georgia: Structural vulnerability and 'Existing not Living'. Human Organization, 74(2), 135-143. doi: 10.17730/0018-7259$\underline{74.2 .135}$

Korobov, N. (2011). Young men's vulnerability in relation to women's resistance to emphasized femininity. Men and Masculinities, 14(1), 51-75. doi:

\section{$\underline{10.1177 / 1097184 X 09356904}$}

Kreager, P., \& Schröder-Butterfill, E. (2007). Gaps in the Family Networks of Older People in Three Indonesian Communities. Journal of Cross-Cultural Gerontology 22 (1), 125. doi: 10.1007/s10823-006-9013-3

Lavee, E. (2017). Low-Income Women's Encounters with Social Services: Negotiation over Power, Knowledge and Respectability. British Journal of Social Work 47 (5), 1554 1571. doi: $\underline{10.1093 / \mathrm{bjsw} / \mathrm{bcw} 131}$

Lombe, M., \& Sherraden, M. (2008). Inclusion in the policy process: An agenda for participation of the marginalized. Journal of Policy Practice, 7(2-3), 199-213. doi: $\underline{10.1080 / 15588740801938043}$ 
Malindi, M., \& Cekiso M. (2014). Exploring the lived experiences of children-of-the-street in Mthatha. Journal of Sociology and Social Anthropology, 5(3), 339-347. doi: $10.1080 / 09766634.2014 .11885638$

Maziarz, M. \& Chertow, G. M. \& Himmelfarb, J. \& Hall, Y. N. (2014). Homelessness and Risk of End-stage Renal Disease. Journal of Health Care for the Poor and Underserved 25(3), 1231-1244. doi: 10.1353/hpu.2014.0136

McLaughlin, K. (2007). Regulation and risk in social work: The General Social Care Council and the Social Care Register in context. The British Journal of Social Work, 37(7), 1263-1277. doi: $10.1093 / \mathrm{bjsw} / \mathrm{bcl079}$

Mishra, A. K. (2014). Safety net measures for unorganised workers in India: Critical gaps and challenges. Social Change, 44(2), 179-203. doi: 10.1177/0049085714526278

Munro, V. E., \& Scoular, J. (2012). Abusing vulnerability? Contemporary law and policy responses to sex work in the UK. Feminist Legal Studies, 20(3), 189-206. doi: $10.1007 / \mathrm{s} 10691-012-9213-\mathrm{x}$

Noble-Carr, D., Barker, J., Mcarthur, M., \& Woodman, E. (2014). Improving practice: The importance of connections in establishing positive identity and meaning in the lives of vulnerable young people. Children and Youth Services Review, 47(3), 389-396. doi: 10.1016/j.childyouth.2014.10.017

Oeye, C., Bjelland, A. K., \& Skorpen, A. (2007). Doing participant observation in a psychiatric hospital: Research ethics resumed. Social Science \& Medicine, 65(11), 2296-2306. doi: 10.1016/j.socscimed.2007.07.016

Orme, J. (2003). 'It's Feminist Because I Say So!' Feminism, Social Work and Critical Practice in the UK. Qualitative Social Work 2(2), 131-153. doi: $10.1177 / 1473325003002002002$ 
Perry, K. H. (2011). Ethics, Vulnerability, and Speakers of Other Languages: How University IRBs (Do Not) Speak to Research Involving Refugee Participants. Qualitative Inquiry 17(10), 899-912. doi: $\underline{10.1177 / 1077800411425006}$

Petticrew, M., \& Roberts, H. (2006). Systematic reviews in the social sciences: A practical guide. Oxford: Blackwell.

Schröder-Butterfill, E., \& Marianti, R. (2006). A framework for understanding old-age vulnerabilities. Ageing \& Society, 26(1), 9-35. doi: 10.1017/S0144686X05004423

Schrover, M. (2009). Family in Dutch migration policy 1945-2005. The History of the Family, 14(2), 191-202. doi: 10.1016/j.hisfam.2009.03.002

Smith, D. E. (1987). The everyday world as problematic: A Feminist sociology. Oxford: Open University Press/Milton Keynes.

Smith, N. A. (2006). Empowering the "Unfit" Mother. Increasing Empathy, Redefining the Label. Affilia: Journal of Women and Social Work 21(4), 448-457. doi:

\section{$\underline{10.1177 / 0886109906292110}$}

Stone, R. (2015). Pregnant women and substance use: Fear, stigma, and barriers to care. Health \& Justice, 3(1), 1-15. doi: 10.1186/s40352-015-0015-5

Swartz, S. (2011). 'Going deep' and 'giving back': Strategies for exceeding ethical expectations when researching amongst vulnerable youth. Qualitative research, 11(1), 47-68. doi: 10.1177/1468794110385885

Szkupinski Quiroga, S., Medina, D. M., \& Glick, J. (2014). In the belly of the beast: Effects of anti-immigration policy on Latino community members. American Behavioral Scientist, 58(13), 1723-1742. doi: $\underline{10.1177 / 0002764214537270}$

Taylor, S. (2011). Educational and Vocational Exploration in Vulnerable Youth. Child \& Youth Services, 32(4), 355-379. doi: 10.1080/0145935X.2011.639254 
Trani, J-F., Bakhshi, P., Noor, A. A, Lopez, D., \& Mashkoor, A. (2010). Poverty, vulnerability, and provision of healthcare in Afghanistan. Social Science \& Medicine, 70(11), 1745-1755. doi: 10.1016/j.socscimed.2010.02.007

Tuchman, E. (2010). Women and addiction: The importance of gender issues in substance abuse research. Journal of Addictive Diseases, 29(2), 127-138. doi: $\underline{10.1080 / 10550881003684582}$

Van de Walle, D. (2013). Lasting welfare effects of widowhood in Mali. World Development, 51(C), 1-9. doi: 10.1016/j.worlddev.2013.05.005

Van Eeuwijk, P. (2006). Old-age vulnerability, ill-health and care support in urban areas of Indonesia. Ageing and Society, 26(1), 61-80. doi: 10.1017/S0144686X05004344

Van Wee, B., \& Banister, D. (2015). How to write a literature review paper? Transport Reviews. A Transnational Transdisciplinary Journal, 36(2), 278-288. doi: $\underline{10.1080 / 01441647.2015 .1065456}$

Vikström, M-C. (2006). Vulnerability among paupers: Determinants of individuals receiving poor relief in nineteenth-century northern Sweden. The History of the Family, 11(4), 223-239. doi: 10.1016/j.hisfam.2006.12.004

Walklate, S. (2011). Reframing criminal victimization: Finding a place for vulnerability and resilience. Theoretical Criminology, 15(2), 179-194. doi: $10.1177 / 1362480610383452$

Wernesjö, U. (2012). Unaccompanied asylum-seeking children: Whose perspective? Childhood, 19(4), 495-507. doi: 10.1177/0907568211429625

Wiles, J. (2011). Reflections on being a recipient of care: vexing the concept of vulnerability. Social \& Cultural Geography, 12(6), 573-588. doi: 10.1080/14649365.2011.601237 
Williams, R. (2009). Masculinities and vulnerability: The solitary discourses and practices of African-Caribbean and white working-class fathers. Men and Masculinities, 11(4), 441-461. doi: 10.1177/1097184X09337931

Wisner, B. (1993). Disaster vulnerability: Scale, power and daily life. Geojournal, 30(2), 127-40. doi: 10.1007/BF00808129 


\begin{tabular}{|c|c|c|c|}
\hline $\begin{array}{l}\quad \begin{array}{l}\text { Inclusion } \\
\text { criteria: }\end{array} \\
\text { Peer reviewed } \\
\text { articles in scientific } \\
\text { journals; published } \\
\text { in English between } \\
2000-2016 \\
\text { Articles where } \\
\text { 'vulnerability' } \\
\text { applies to people or } \\
\text { their life situations } \\
\text { and is being } \\
\text { defined or } \\
\text { conceptualised } \\
\text { Available free of } \\
\text { charge via } \\
\text { University Library } \\
\text { databases }\end{array}$ & $\begin{array}{l}\text { Search term: } \\
\text { vulnerability OR } \\
\text { vulnerable } \\
\text { (=keyword) } \\
\text { Databases: } \\
\text { Social Services } \\
\text { Abstracts } \\
\text { Sociological } \\
\text { Abstracts } \\
\rightarrow \\
\mathbf{4 7 9} \text { articles }\end{array}$ & $\begin{array}{l}\text { Articles scanned } \\
\text { through (titles, } \\
\text { abstracts \& } \\
\text { keywords) } \\
\text { Excluded those } \\
\text { that did not meet } \\
\text { the inclusion } \\
\text { criteria ( } 366 \\
\text { articles) } \\
\text { Articles } \\
\text { categorised } \\
\text { according to their } \\
\text { topic }\end{array}$ & $\begin{array}{l}\text { Careful reading of } \\
\text { the articles } \\
\text { Summaries written } \\
\text { based on the } \\
\text { research questions } \\
\text { Further } 25 \text { articles } \\
\text { excluded }\end{array}$ \\
\hline
\end{tabular}

Figure 1: The process of literature review 